\title{
Picture Superiority Doubly Dissociates the ERP Correlates of Recollection and Familiarity
}

\author{
Tim Curran and Jeanne Doyle
}

\begin{abstract}
Two experiments investigated the processes underlying the picture superiority effect on recognition memory. Studied pictures were associated with higher accuracy than studied words, regardless of whether test stimuli were words (Experiment 1) or pictures (Experiment 2). Event-related brain potentials (ERPs) recorded during test suggested that the 300-500 msec FN400 old/ new effect, hypothesized to be related to familiarity-based recognition, benefited from study/test congruity, such that it was larger when study and test format remained constant than when they differed. The 500-800 msec parietal old/new effect, hypothesized
\end{abstract}

\section{INTRODUCTION}

It is well known that pictures are typically remembered better than words, but the explanation of this "picture superiority effect" continues to be debated. Paivio's (1976, 1986) dual-coding hypothesis suggests that pictures are better remembered because they are encoded into both verbal and image codes compared to words that are primarily coded verbally. Others have suggested that pictures are better remembered than words because pictures are more distinctive (Mintzer \& Snodgrass, 1999) in their visual features (Nelson, Reed, \& Walling, 1976) or their semantic/conceptual features (Weldon, Roediger, \& Challis, 1989; Weldon \& Roediger, 1987). Within the domain of recognition memory, some have tried to assess whether picture superiority influences either the familiarity and/or recollection processes thought to underlie recognition memory according to the dual-process perspective (reviewed by Eichenbaum, Yonelinas, \& Ranganath, 2007; Yonelinas, 2002), not to be confused with Paivio's "dual coding" in the present context. Recollection contributes to recognition through the recall of specific details from the study episode, whereas familiarity influences recognition without the recall of details. The present research extends this dual-process approach by measuring ERPs during recognition memory tests to better understand the processes underlying this effect as well as to use the picture superiority effect as a way to dissociate familiarity from recollection.

University of Colorado at Boulder to be related to recollection, benefited from studying pictures, regardless of test format. The parallel between the accuracy and parietal ERP results suggests that picture superiority may arise from encoding the distinctive attributes of pictures in a manner that enhances their later recollection. Furthermore, when words were tested, opposite effects of studying words versus studying pictures were observed on the FN400 (word $>$ picture) versus parietal (picture $>$ word) old/new effects-providing strong evidence for a crossover interaction between these components that is consistent with a dual-process perspective.

The picture superiority effect has been attributed to recollection more so than familiarity. This perspective potentially ties into the distinctiveness view because other research has emphasized the importance of distinctiveness for enhancing recollection (Gallo, Cotel, Moore, \& Schacter, 2007; Gallo, Weiss, \& Schacter, 2004; Reder, Donavos, \& Erickson, 2002). Using the "remember/know" procedure, the recognition accuracy advantage for studied pictures over words has been reported to be associated primarily with "remember" responses that are thought to be indicative of recollection (Rajaram, 1996; Dewhurst \& Conway, 1994). However, these results are readily interpretable from a single-process perspective in which remembering and knowing merely reflect memory strength differences, as might be observed as different confidence levels (Wixted, 2007; Dunn, 2004). Similarly, the process dissociation procedure has been used to examine the picture superiority effect on a number of implicit memory tasks, suggesting that conscious memory influences (perhaps related to recollection) were stronger for pictures than words (McBride \& Anne Dosher, 2002), but it is unclear how these results apply to the recognition memory tasks of interest here.

Another approach toward differentiating familiarity from recollection is the response-signal, speed-accuracy tradeoff method whereby accuracy is measured when subjects are forced to respond at various points in time following the onset of the test items. Previous research has suggested that fast responses are indicative of familiarity, whereas recollection comes into play on later responses (McElree, Dolan, \& Jacoby, 1999; Hintzman \& Curran, 1994). This method was applied to the picture 
superiority effect in experiments in which subjects studied pictures or words, followed by recognition memory tests with words that were either studied, names of studied pictures, or new (Boldini, Russo, Punia, \& Avons, 2007). Faster responses were more accurate for studied words than studied pictures, whereas slower responses were more accurate for studied pictures than studied words. One interpretation of this pattern is that fast familiarity processes benefited from the perceptual match of words being both studied and tested, whereas slower recollection processes benefited from the greater distinctiveness of studied pictures. Boldini et al. (2007) cautiously advanced this dual-process perspective, but also acknowledged singleprocess alternatives that have been offered for similar speed-accuracy tradeoff results. That is, word/picture differences may reflect differences in the time course of perceptual processes needed to support memory for pictures versus words rather than differences in retrieval processes per se (Brockdorff \& Lamberts, 2000).

ERPs have also been used to separate recollection from familiarity. In recognition memory experiments primarily comparing ERPs associated with hits to correct rejections ("old/new effects"), familiarity has been associated with a 300-500 msec mid-frontal old/new difference, often called the "FN400," whereas recollection has been associated with a 500-800 msec parietal old/new effect (reviewed by Rugg \& Curran, 2007; Curran, Tepe, \& Piatt, 2006; Mecklinger, 2006; Friedman \& Johnson, 2000; Mecklinger, 2000). The parietal old/new effect has been linked to the recollection of specific details from study episodes such as the plurality of words (Curran, 2000), orientation of pictures (Curran \& Cleary, 2003), or occupations associated with faces (Curran \& Hancock, 2007), whereas these same studies have found that the FN400 familiarity effect differentiates old from new items without being sensitive to the recollection of details. Similarly, the parietal recollection effect, but not the FN400 familiarity effect, has been associated with accurate source recognition (Senkfor \& Van Petten, 1998; Wilding \& Rugg, 1996), the subjective experience of "remembering" (Curran, 2004; Trott, Friedman, Ritter, Fabiani, \& Snodgrass, 1999; Rugg, Schloerscheidt, \& Mark, 1998; Düzel, Yonelinas, Mangun, Heinze, \& Tulving, 1997; Smith, 1993), and the amnestic effects of the studyphase administration of midazolam. On the other hand, the FN400 familiarity effect, but not the parietal recollection effect, has been shown to vary continuously with response bias (Azimian-Faridani \& Wilding, 2006).

Most previously reported differences between the FN400 and parietal effects represent single dissociations such that a variable affects one process, but not the other. To our knowledge, only three double dissociations have been reported. Woodruff, Hayama, and Rugg (2006) performed a modified remember/know task in which test items that were not "remembered" were rated on a 4-point confidence scale. The FN400 magnitude varied with confidence that an item was old, but did not differ according to whether test items were "remembered" or were given the highest confidence rating. Conversely, the parietal old/new effect was selectively enhanced for remembered items, but did not vary with confidence for items that were not recollected. Thus, "remembering" selectively influenced the parietal effect, whereas sub-recollection confidence level selectively influenced the FN400. Stenberg, Hellman, Johansson, and Rosén (2009) tested memory for names and showed that the FN400 was selectively affected by the commonness of names, whereas the parietal old/new effect was selectively affected by fame. As explained more thoroughly within the General Discussion, such "uncrossed double dissociations" are limited by the presence of null effects on each component. Crossover double dissociations, where the same variable affects each component in opposite ways, are potentially more powerful. Such a crossover interaction was reported in a study of associative recognition for faces, where the FN400 effect was larger for intra- than for interitem associations, but the parietal effect showed the opposite pattern (Jager, Mecklinger, \& Kipp, 2006).

Several previous ERP studies have explored the picture superiority effect. Two of these studies manipulated study format between subjects (Budson et al., 2005) or between blocks (Hornberger, Morcom, \& Rugg, 2004) because they were primarily interested in retrieval orientation effects that influence how subjects' strategies change following the study of only words or only pictures. Although such retrieval orientation effects are interesting, we instead will focus only on experiments using mixed study lists of words or pictures that are more sensitive to discrimination differences between old words and old pictures rather than retrieval orientation strategies or response bias. Two such ERP studies found that the FN400 benefits from the congruency of study and test conditions, such as cases where words are both studied and tested or pictures are both studied and tested, over conditions where word/ picture status changes from study to test (Ally \& Budson, 2007; Schloerscheidt \& Rugg, 2004, hereafter A\&B and $\mathrm{S} \& \mathrm{R})$. These results are generally consistent with others showing that the FN400 is sensitive to the perceptual match between study and test conditions (Nyhus \& Curran, 2009; Ecker, Zimmer, \& Groh-Bordin, 2007a, 2007b; Groh-Bordin, Zimmer, \& Ecker, 2006). The parietal results were somewhat mixed in the aforementioned picture superiority experiments with S\&R finding that the parietal old/new effect also benefited from study/test matching, but A\&B finding that the effect was marginally smaller for studied words than studied pictures (collapsed across test type).

Previous ERP studies of the picture superiority effect did not observe a particularly interesting behavioral pattern that is often reported in the literature. The picture superiority effect can be observed even when pictures are studied and corresponding words are tested (Hockley, 2008; Boldini et al., 2007; Stenberg, Radeborg, \& Hedman, 1995; Madigan, 1983; Paivio, 1976; Snodgrass \& McClure, 1975). This is interesting because memory is better for perceptually incongruent (picture/word) than congruent (word/word) 
study/test conditions. Accuracy was similar for words and pictures in both ERP studies (word/word $=86 \%$, picture/ word $=87 \%$, A\&B; word $/$ word $=87 \%$, picture/word $=85 \%$, S\&R). ${ }^{1}$ On the other hand, Boldini et al.'s speed-accuracy tradeoff study found that asymptotic accuracy was higher in the picture/word than word/word condition when recollection should contribute to performance, but accuracy was higher for the word/word than picture/word condition for faster responses that should be dominated by familiarity. Based on these results, one would predict that earlier, familiarity-related FN400 ERP old/new effects should be larger for word/word than picture/word, but later recollectionrelated parietal old/new effects should be larger for picture/ word than word/word. S\&R reported trends consistent with these predictions, but the predicted differences were not significant. Because A\&B's analyses were not tailored to assessing these specific effects, the relevant statistics were not reported, but results presented within their figures seem entirely consistent with these predictions. In addition to the importance of these predicted effects for understanding the processes underlying the picture superiority effect, they are also more generally important for predicting a clear crossover double dissociation between the FN400 (word/ word $>$ picture/word) and parietal (word/word $<$ picture/ word) components.

\section{EXPERIMENT 1}

Experiment 1 required subjects to study mixed lists of words and pictures that they were asked to read/name aloud followed by a recognition test with words that were either studied words (word/word), the names of studied pictures (picture/word), or not studied (new). Pilot testing insured that accuracy would be higher in the picture/ word than word/word conditions. We predicted that 300500 msec mid-frontal FN400 ERP old/new effects should be larger for word/word than picture/word conditions, but 500-800 msec parietal old/new effects should be larger for picture/word than word/word conditions. This prediction is consistent with trends reported in previous ERP studies (Ally \& Budson, 2007; Schloerscheidt \& Rugg, 2004), other ERP experiments showing that the FN400 is enhanced by study/test congruity (Nyhus \& Curran, 2009; Ecker et al., 2007a, 2007b; Groh-Bordin et al., 2006), Boldini et al.'s (2007) speed-accuracy tradeoff study showing an early word/word advantage followed by a later picture/ word advantage, as well as remember/know studies suggesting a recollective basis for the picture superiority effect (Rajaram, 1996; Dewhurst \& Conway, 1994).

\section{Methods}

\section{Participants}

Thirty-two right-handed participants were paid $\$ 15 /$ hour or given credit for a University of Colorado course requirement. Of these 32, data from 5 participants were discarded be- cause of excessive eye movement artifacts or bad electrodes. Of the 27 subjects retained for analysis, 15 were women.

\section{Design}

The experiment included three conditions that were all manipulated within subjects and mixed within lists: studied words, studied pictures, and new (nonstudied) words.

\section{Stimuli}

Three hundred line drawings of common objects and their corresponding names comprised the experimental stimuli. For each subject, stimuli were randomly assigned to one of three conditions: studied pictures, studied words, or nonstudied. All pictures and words were obtained from the IPNP on-line database (http://crl.ucsd.edu/ aszekely/ ipnp/; Szekely et al., 2004), which includes 174 of the stimuli from Snodgrass and Vanderwart (1980). All stimuli were chosen according to word length $(<10$ letters) and percent name agreement $(>82 \%)$, which is the percent of trials that Szekely et al.'s (2004) participants named a picture with the corresponding target word. An additional 26 practice stimuli (10 pictures, 16 words) and 20 buffer stimuli (10 pictures, 10 words) did not meet these criteria. The pictures were presented in black and white, and the words were presented in white on a black background. All stimuli were viewed on an LCD computer monitor.

\section{Procedure}

Participants were given verbal and written instruction for a practice version of the experiment, which was identical to one experimental study and test block in every respect but length (10 study pictures, 10 study words, and 6 new test words during the practice). After completing the practice test, the participant was fitted with a Geodesic Sensor Net. Following net application, the subjects took approximately 1.5 hours to complete five study/test blocks.

Each of five study lists included 20 pictures and 20 words, shown one at a time alternating between picture and word format. There were two nontested buffers at the beginning and end of each study list to absorb primacy and recency effects. Each studied picture or word appeared on the center of the screen for 2000 msec with a 1000-msec ISI. Subjects were instructed to name each picture or read each word out loud, while the experimenter wrote down their verbal responses.

During each test list, subjects were presented with words belonging to three different conditions: 20 words that were studied in word format (word/word), 20 words that were names of studied pictures (picture/word), and 20 new nonstudied words. Before each word, there was a randomly timed fixation cross (between 500 and $1000 \mathrm{msec}$ ). Each word appeared for $2 \mathrm{sec}$ after which the participant was shown a question mark ("?"). Subjects were instructed to withhold their responses until the question mark appeared, 
otherwise they were informed that they responded too quickly. A 1000-msec ISI followed each response. Participants indicated whether the test word was old or new by pressing one of two keys on a vertically aligned response box with their right and left index fingers. Assignment of left/right fingers to old/new keys was counterbalanced across subjects. Subjects were instructed to limit blinking and movement. Subject-timed blink breaks were given after every 15 words.

\section{EEG/ERP Methods}

Scalp voltages were collected with a 128-channel HydroCel Geodesic Sensor Net connected to AC-coupled, 128-channel, high-input impedance amplifiers (200 M $\Omega$, Net Amps; Electrical Geodesics Inc., Eugene, OR). Amplified analog voltages (0.1-100 Hz bandpass) were digitized at $250 \mathrm{~Hz}$. Individual sensors were adjusted until impedances were less than $50 \mathrm{k} \Omega$.

The EEG was digitally low-pass filtered at $40 \mathrm{~Hz}$ prior to ERP analysis. Trials were discarded from analysis if they contained incorrect responses or more than $20 \%$ of the channels were bad (average amplitude over $100 \mu \mathrm{V}$ or voltage fluctuations of greater than $50 \mu \mathrm{V}$ between adjacent samples). Individual bad channels were replaced on a trialby-trial basis with a spherical spline algorithm (Srinivasan, Nunez, Silberstein, Tucker, \& Cadusch, 1996). Eye movements were corrected using an ocular artifact detection algorithm (Gratton, Coles, \& Donchin, 1983). EEG was mea- sured with respect to a vertex reference $(\mathrm{Cz})$. ERPs were re-referenced to an average reference, the voltage difference between that channel and the average of all channels, to minimize the effects of reference site activity and to improve estimates of electrical field topography (Dien, 1998). The average reference was corrected for the polar average reference effect (Junghöfer, Elbert, Tucker, \& Braun, 1999). ERPs were baseline corrected to a 200-msec prestimulus recording interval.

\section{Results}

All $p$ values from repeated measures ANOVAs were corrected for violations of the sphericity assumption using the method of Geisser and Greenhouse (1958).

\section{Behavioral Results}

Accuracy. Proportion correct was analyzed in a threecondition (new, picture, and word) repeated measures ANOVA. The main effect of condition was significant $[F(2$, $52)=43.60, M S E=0.01, p<.0001]$. Subjects were significantly more accurate for pictures than words, demonstrating a picture superiority effect $[F(1,52)=77.07, M S E=0.01$, $p<.0001$; see Figure 1, left].

Reaction time (RT). The condition effect on RT was also significant $[F(2,52)=7.14, M S E=6434, p<.01$;
Figure 1. Mean proportion correct in Experiments 1 and 2. Error bars are standard error of the mean.

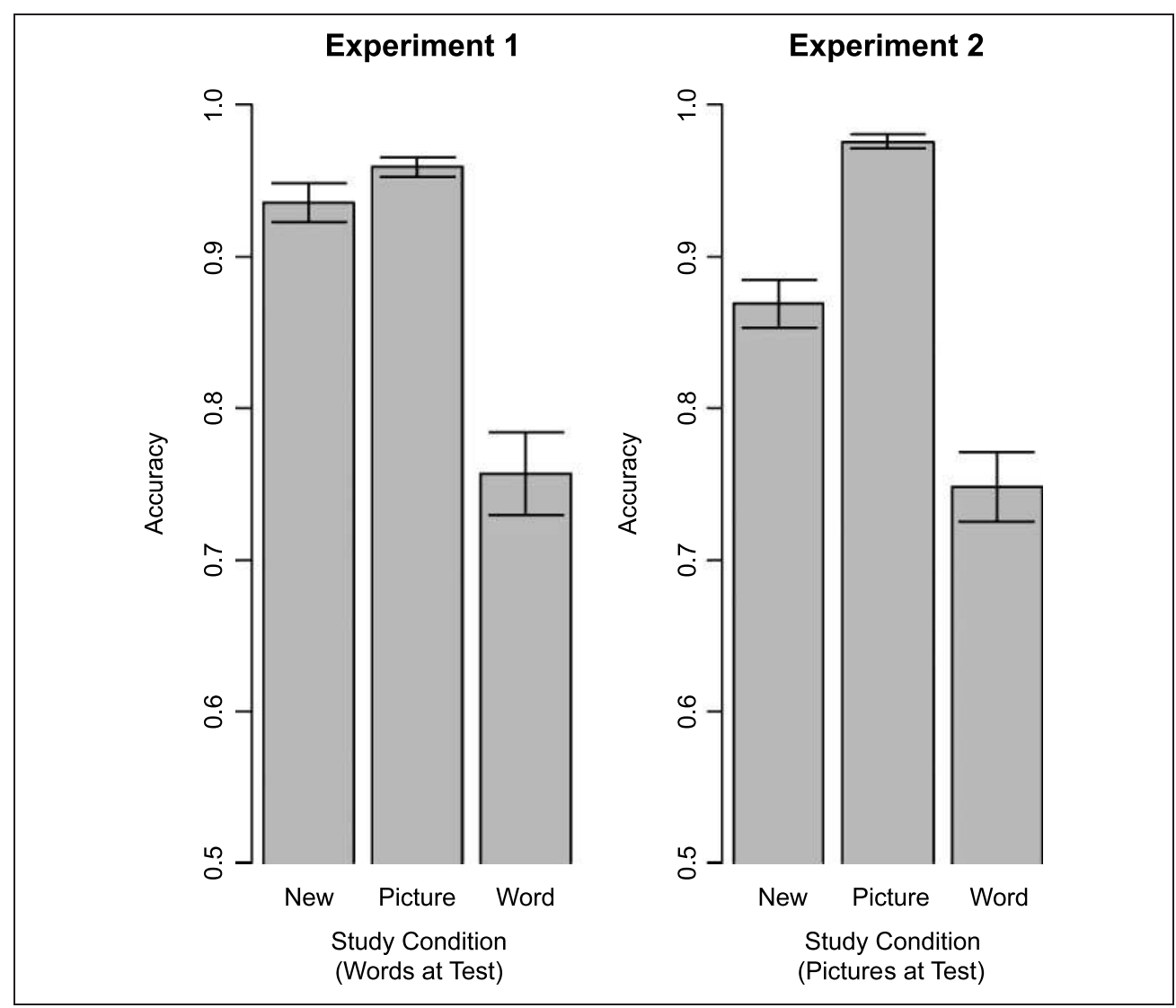


Figure 2. Sensor layout along with analysis clusters. $\mathrm{L}=$ left; $\mathrm{R}=$ right; $\mathrm{A}=$ anterior; $\mathrm{P}=$ posterior; $\mathrm{I}=$ inferior; $\mathrm{S}=$ superior.

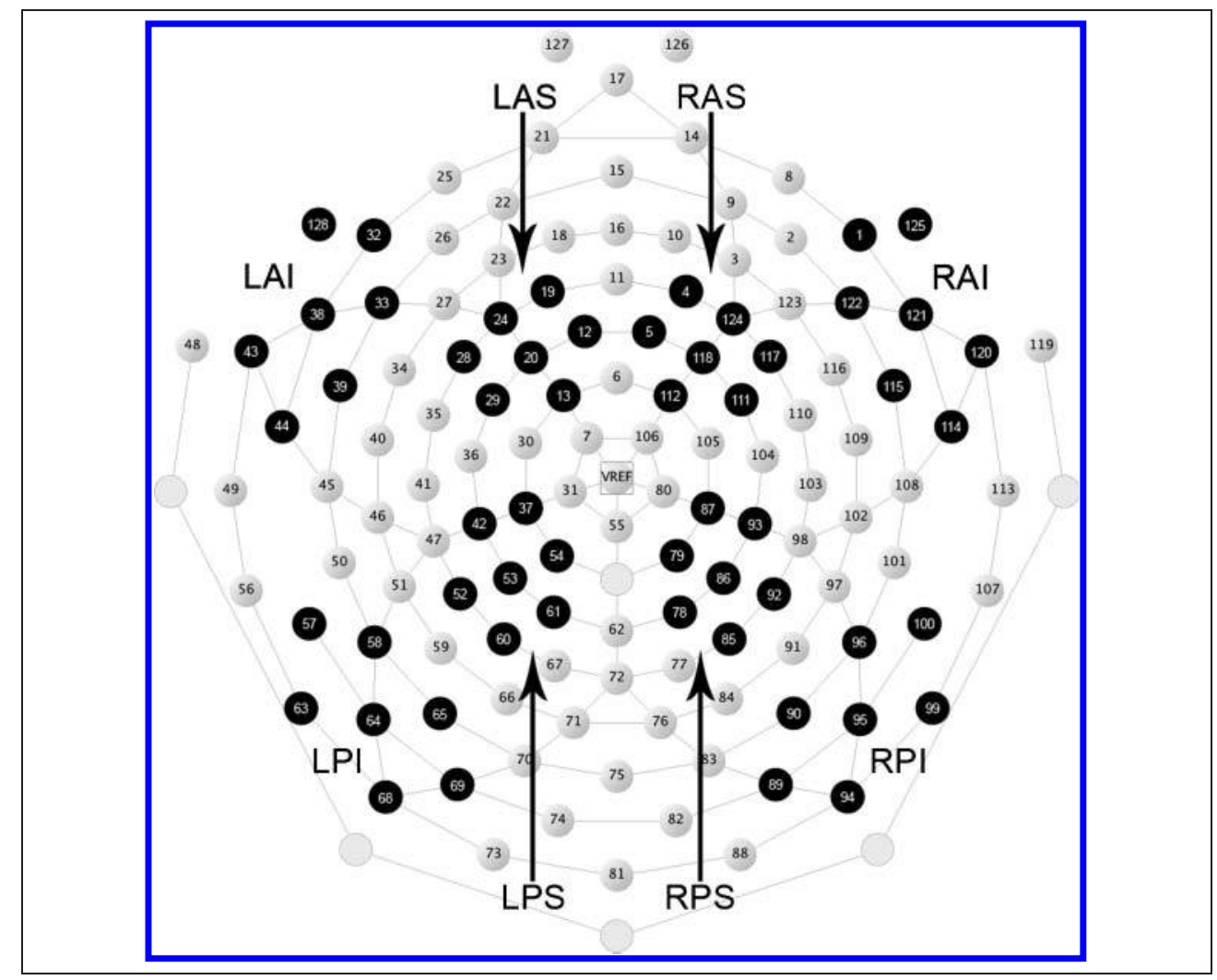

including only the accurate trials]. The RT for studied pictures was faster ( $M=2434 \mathrm{msec}, S E=28 \mathrm{msec}$ ) than both the new and word conditions, both $p<.01$, but the new $(M=2516 \mathrm{msec}, S E=37 \mathrm{msec})$ and word $(M=$ $2465 \mathrm{msec}, \mathrm{SE}=29 \mathrm{msec}$ ) RTs did not differ. RTs were artificially inflated by the requirement to withhold a response until the test word appeared $(2000 \mathrm{msec}$ after onset), so should be interpreted accordingly.

\section{ERP Results}

ERPs were analyzed at locations and time points consistent with previous research (Curran \& Hancock, 2007; Curran, DeBuse, Woroch, \& Hirshman, 2006; Curran, 2004). The FN400 was measured over two superior/anterior channel groups from 300 to 500 msec. These are labeled left and right anterior/superior regions (LAS and RAS; see Figure 2). The parietal old/new effect was analyzed over two posterior, superior channel groups from 500 to $800 \mathrm{msec}$. These are labeled left and right posterior/superior regions (LPS and RPS; see Figure 2). Grand-average ERPs within these four regions are shown in Figure 3. For both components, the dependent measure was mean voltage amplitude, averaged within the locations and time points of interest. ${ }^{2}$

FN400. The FN400 effect was analyzed in a 3 Condition (new, word, picture) $\times 2$ Hemisphere (LAS, RAS) repeated measures ANOVA. The main effect of condition was significant $[F(2,52)=3.19, M S E=0.65, p<.05]$, as well as the interaction between condition and hemisphere $[F(2,52)=$
7.25, MSE $=0.11, p<.01]{ }^{3}$ Pairwise comparisons indicate that the FN400 old/new differences in the RAS region were significant only for studied words $(p<.001)$, but not for studied pictures (see Figure 4A for mean amplitudes in each condition). RAS differences between studied words and studied pictures were also significant $(p<.001)$. However, old/new FN400 differences in the LAS region were significant for both words and pictures; the amplitudes were more negative for new stimuli versus studied pictures $(p<$ $.001)$ and new stimuli versus studied words $(p<.001)$.

Parietal. The parietal effect was analyzed in a 3 Condition (new, word, picture) $\times 2$ Hemisphere (LPS, RPS) ANOVA from 500 to $800 \mathrm{msec}$. The main effect of condition was significant $[F(2,52)=3.62, M S E=0.73, p<.05]$, as well as the interaction between condition and hemisphere $[F(2$, $52)=6.48, M S E=0.17, p<.01]$. Old $/$ new differences were only present in the LPS region and were significant only for pictures (Figure 4B). Pairwise comparisons indicate that left parietal amplitudes were significantly more positive for studied pictures compared to either studied words $(p<.001)$ or new words $(p<.001)$.

FN400 vs. parietal effects. The previous results suggest a crossover double dissociation such that the FN400 old/ new effects were larger for words than pictures, but the parietal effects were larger for pictures than words. Evidence for such a double dissociation would be stronger if the two effects were directly compared, thus a 2 Component $(\mathrm{FN} 400$, parietal) $\times 2$ Condition (word, picture) $\times$ 
2 Hemisphere (left, right) ANOVA was conducted. As in the previous analyses, FN400 amplitudes came from anterior, superior regions and parietal amplitudes came from posterior, superior regions. The significant Component $\times$ Condition interaction confirmed that the word/picture manipulation at study produced opposite effects on the FN400 (word $>$ picture) versus parietal (word $<$ picture) components $[F(1,26)=6.09$, MSE $=0.61, p<.05]$. Despite the hemispheric differences reported in the separate analyses above, the Component $\times$ Condition $\times$ Hemisphere interaction was not significant $[F(1,26)<1]$.

Topographic analysis. The foregoing analyses focused on separate 300-500 msec anterior FN400 effects and 500$800 \mathrm{msec}$ posterior parietal effects based on regions of interest identified in previous research. We verified the distinct topographies of the two effects in a topographic analysis involving the eight clusters of sensors depicted in Figure 2. To focus on qualitative differences unconfounded by overall amplitude (McCarthy \& Wood, 1985), the topographic analysis used range-normalized (McCarthy \& Wood's, 1985 max-min method) old/new differences as the dependent measure in a 2 Time $(300-500,500-800 \mathrm{msec}) \times 2$ Condition (picture-new, word-new) $\times 2$ Hemisphere $\times 2$ Anterior/ Posterior $\times 2$ Inferior/Superior repeated measures ANOVA. Although several lower-order interactions were observed, their interpretations were superseded by a significant Time $\times$ Condition $\times$ Hemisphere $\times$ Anterior/Posterior interaction $[F(1,26)=5.02, M S E=0.12, p<.05]$. As can be observed in the topographic maps of old/new differences depicted in Figure 5, the most prominent old/new difference during the 300-500 msec time frame of the FN400 was observed over anterior regions for studied words, whereas the most prominent old/new difference observed during the 500 $800 \mathrm{msec}$ time frame of the parietal effects was observed over left, posterior regions for studied pictures. Thus, this analysis replicates the topographic differences between the FN400 and parietal effects observed in previous research, upholds the appropriateness of the anterior (FN400) versus posterior (parietal) regions of interest used in the primary analyses, and again confirms the Word/Picture $\times$ Component interaction documented in previous analyses.

\section{Discussion}

Accuracy on recognition memory tests with words was higher when those words named studied pictures than when those words actually appeared on the study list. Thus, a picture superiority effect was observed that transcended study/test compatibility, as in previous studies (Hockley, 2008; Boldini et al., 2007; Stenberg et al., 1995; Madigan, 1983; Paivio, 1976; Snodgrass \& McClure, 1975). As predicted, FN400 old/new differences were larger when words were studied and tested, but parietal old/new differences were larger when test words were studied as pictures. These results are consistent with the idea that early familiarity effects, indexed by the FN400, are enhanced by perceptual congruence between study and test (Nyhus \& Curran, 2009; Ecker et al., 2007a, 2007b; Groh-Bordin et al., 2006), yet picture superiority effects that overshadow these congruence effects are attributable to a later recollection process, indexed by the parietal old/new effect. The significant crossover interaction between study stimulus and ERP components confirms a double dissociation between these components.
Figure 3. Grand-average ERPs from Experiment 1. LAS $=$ left, anterior, superior; RAS $=$ right, anterior, superior; LPS $=$ left, posterior, superior; RPS = right, posterior, superior.

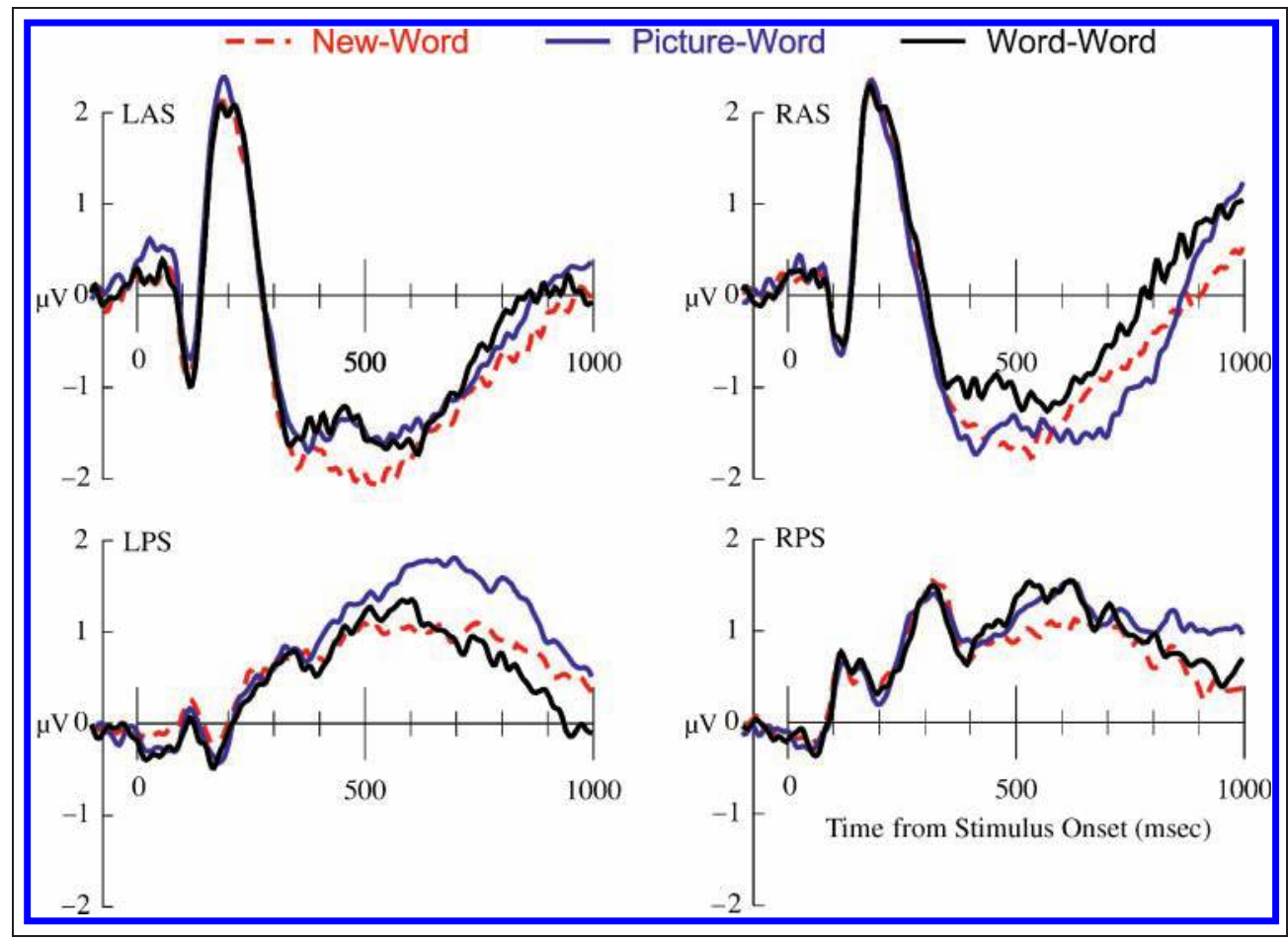




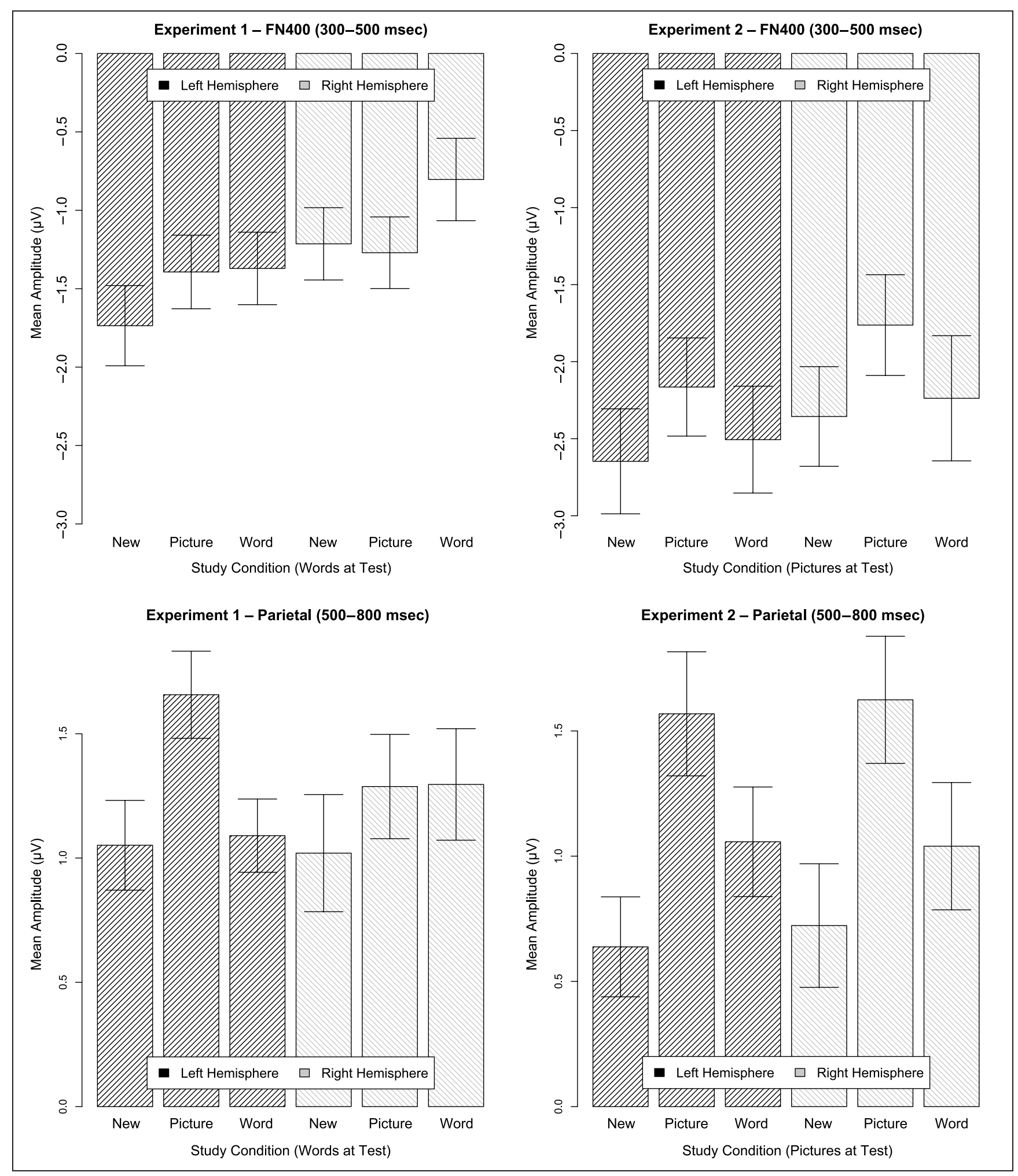

Figure 4. Mean amplitudes for Experiment 1 (left) and Experiment 2 (right) for the FN400 measured over anterior, superior sensor clusters (top) and the parietal effects measured over posterior, superior clusters (bottom). Error bars are standard error of the mean.

In addition to these predicted effects, some interesting laterality results were observed. Parietal old/new effects were left lateralized, as is typically observed. FN400 old/new effects were observed for both studied words and studied pictures over the left hemisphere, but were observed for only studied words over the right hemisphere. These results are generally consistent with previous suggestions that right hemisphere memory processes better retain the perceptual details of studied experiences, whereas left hemisphere processes represent experiences more abstractly (Laeng, 
Overvoll, \& Steinsvik, 2007; Metcalfe, Funnell, \& Gazzaniga, 1995; Marsolek, Squire, Kosslyn, \& Lulenski, 1994). From this perspective, FN400 effects maximal over the left hemisphere may tap into abstract representations that would support memory both within (word/word) and across (picture/ word) formats, whereas those over the right hemisphere reflect perceptually specific representations that require constant perceptual formats (word/word but not picture/word).

\section{EXPERIMENT 2}

Experiment 2 repeated the study conditions of Experiment 1 , but only pictures (rather than words) were presented during test. This was done for several reasons. First, it completed the design of Experiment 1, so all possible study/test combinations were examined over the two experiments. Second, it provided a second test of our general prediction that the FN400 would benefit from study/ test congruence, but the parietal effect would show picture superiority. Thus, we predicted that both the FN400 and the parietal effect would be larger when pictures were studied and tested than when words were studied and pictures were tested. Third, it provided an opportunity to replicate the intriguing FN400 laterality results from Experiment 1. If the pattern observed in Experiment 1 reflects reliable differences between abstract left hemisphere processes and perceptually specific right hemisphere pro- cesses, then we should observe left-lateralized old/new difference for both studied pictures and studied words, whereas we should observe right-lateralized old/new differences for only pictures when pictures are tested.

\section{Methods}

\section{Participants}

Thirty-seven right-handed participants were paid $\$ 15 /$ hour or given credit for a University of Colorado course requirement. Of these 37 , data from eight participants were discarded because of extremely low hit rates to words ( $n=$ $5)$, extremely slow RT $(n=1)$, low naming accuracy $(n=$ 1 , nonnative speaker), or a computer crash $(n=1)$. Of the 29 subjects retained for analysis, 10 were women.

\section{Design and Procedure}

The study phase was identical to Experiment 1 . The test phase was the same as Experiment 1, except that it included only pictures rather than words.

\section{Results}

\section{Behavioral Results}

Accuracy. Proportion correct was analyzed in a 3 Condition (new, picture, and word) ANOVA. The main effect of
Figure 5. Topographic maps of old/new differences from Experiment 1.

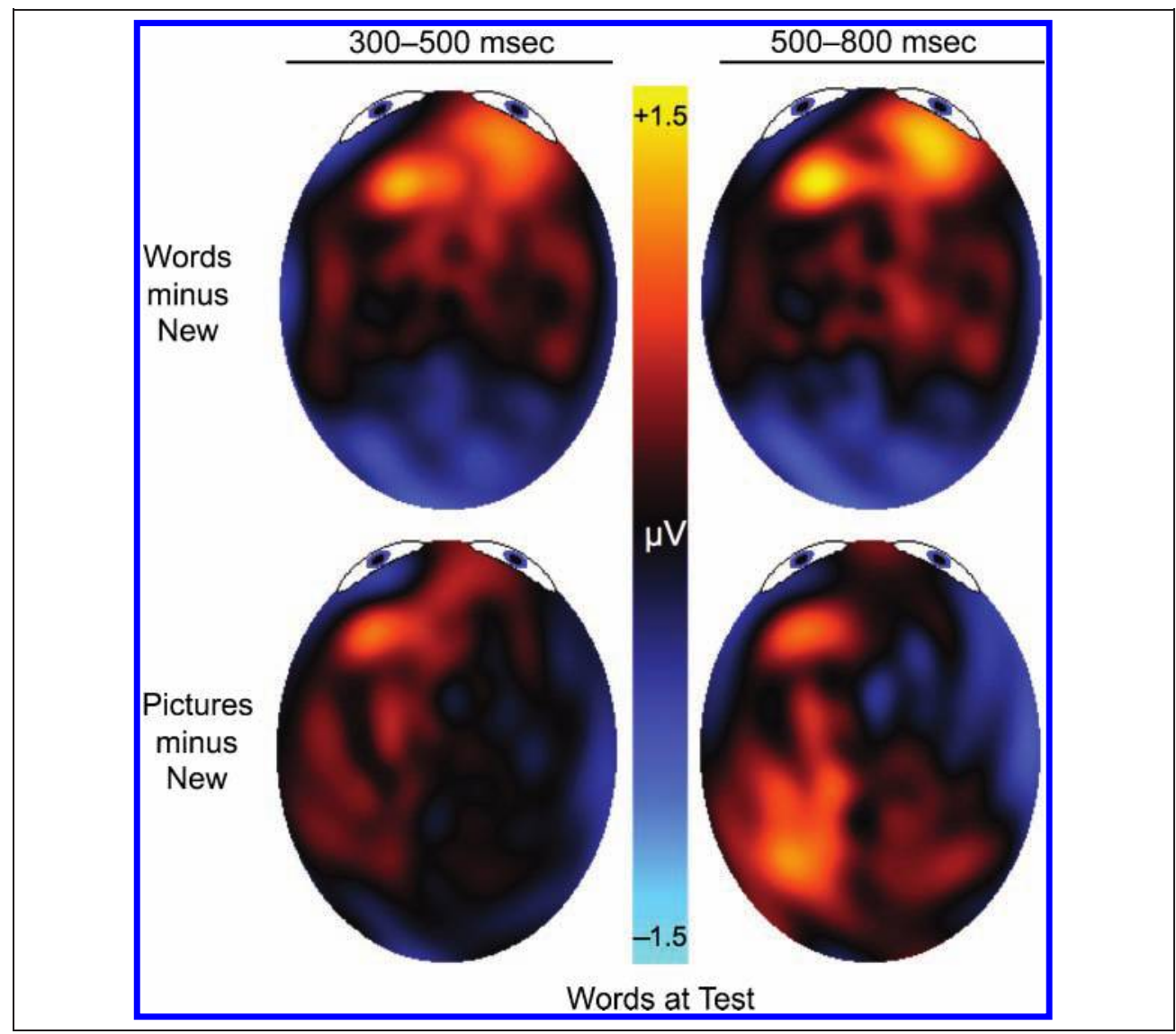


Table 1. Mean (SE) Discrimination $\left(d^{\prime}\right)$ and Response Bias (c)

\begin{tabular}{|c|c|c|c|c|}
\hline \multirow[b]{2}{*}{ Study: } & \multicolumn{2}{|c|}{ Experiment 1} & \multicolumn{2}{|c|}{ Experiment 2} \\
\hline & Picture & Word & Picture & Word \\
\hline Test: & Word & Word & Picture & Picture \\
\hline$d^{\prime}$ & $3.51(.15)$ & $2.47(.15)$ & $3.22(.10)$ & $1.92(.10)$ \\
\hline$c$ & $-0.05(.06)$ & $0.46(.07)$ & $-0.41(.06)$ & $0.24(.06)$ \\
\hline
\end{tabular}

condition was significant $[F(2,56)=44.82, M S E=0.01$, $p<.0001]$. Subjects were significantly more accurate for pictures than words, demonstrating a picture superiority effect $[F(1,56)=120.53, M S E=0.01, p<.0001$; see Figure 1 , right].

Our primary analyses within each experiment compared accuracy (hit rates) between pictures and words, rather than computing discrimination or bias measures because the single new condition within each experiment would have made any discrimination or bias differences completely attributable to the hit rates. However, to compare the performance between experiments, discrimination $\left(d^{\prime}\right)$ and response bias $(c$, where negative values are liberal and positive values are conservative) measures were calculated, as shown in Table 1 . An Experiment $\times$ Study condition (word, picture) ANOVA on $d^{\prime}$ resulted in main effects of experiment $[F(1,54)=6.25, M S E=0.78, p<.05]$ and condition $[F(1,54)=458, M S E=0.08, p<.001]$, as well as a significant Experiment $\times$ Condition interaction $[F(1$, $54)=6.07, M S E=0.08, p<.05]$. Paired comparison indicated that discrimination of studied words was higher in Experiment 1 than in Experiment $2(p<.01)$, but the difference between experiments was not significant for studied pictures. The lack of picture differences between experiments may be due to a ceiling effect, whereas the better discrimination for words studied in Experiment 1 is likely due to study/test format congruency.

Response bias was more conservative in Experiment 1 than in Experiment $2[F(1,54)=11.81, M S E=0.20, p<$ $.01]$, and more conservative for studied words than studied pictures $[F(1,54)=458, M S E=0.02, p<.001]$. The Experiment $\times$ Study condition interaction indicated that the difference between experiments was larger for studied pictures than words $[F(1,54)=6.07, M S E=0.02, p<$ $.02]$, but the experiment effects were significant within each condition separately (both $p<.05$ ). Higher discrimination in Experiment 1 could explain the more conservative responding in that experiment (Stretch \& Wixted, 1998; Hirshman, 1995).

Reaction time. The condition effect on RT for accurate trials was also significant $[F(2,56)=16.60, M S E=6206$, $p<.01]$. All pairwise differences were significant $(p<$ $.01)$ : picture $(M=2465 \mathrm{msec}, S E=27 \mathrm{msec})<$ word $(M=2497 \mathrm{msec}, S E=27 \mathrm{msec})<$ new $(M=2581 \mathrm{msec}$, $S E=37 \mathrm{msec})$.

\section{ERP Results}

FN400. The FN400 effect was analyzed in a 3 Condition (new, picture, word) $\times 2$ Hemisphere $($ LAS, RAS) repeated measures ANOVA from 300 to $500 \mathrm{msec}$. The main effect of condition was significant $[F(2,56)=8.09, M S E=0.56$, $p=.001]$, but the interaction between condition and
Figure 6. Grand-average ERPs from Experiment 2. LAS $=$ left, anterior, superior; RAS $=$ right, anterior, superior; LPS $=$ left, posterior, superior; RPS = right, posterior, superior.

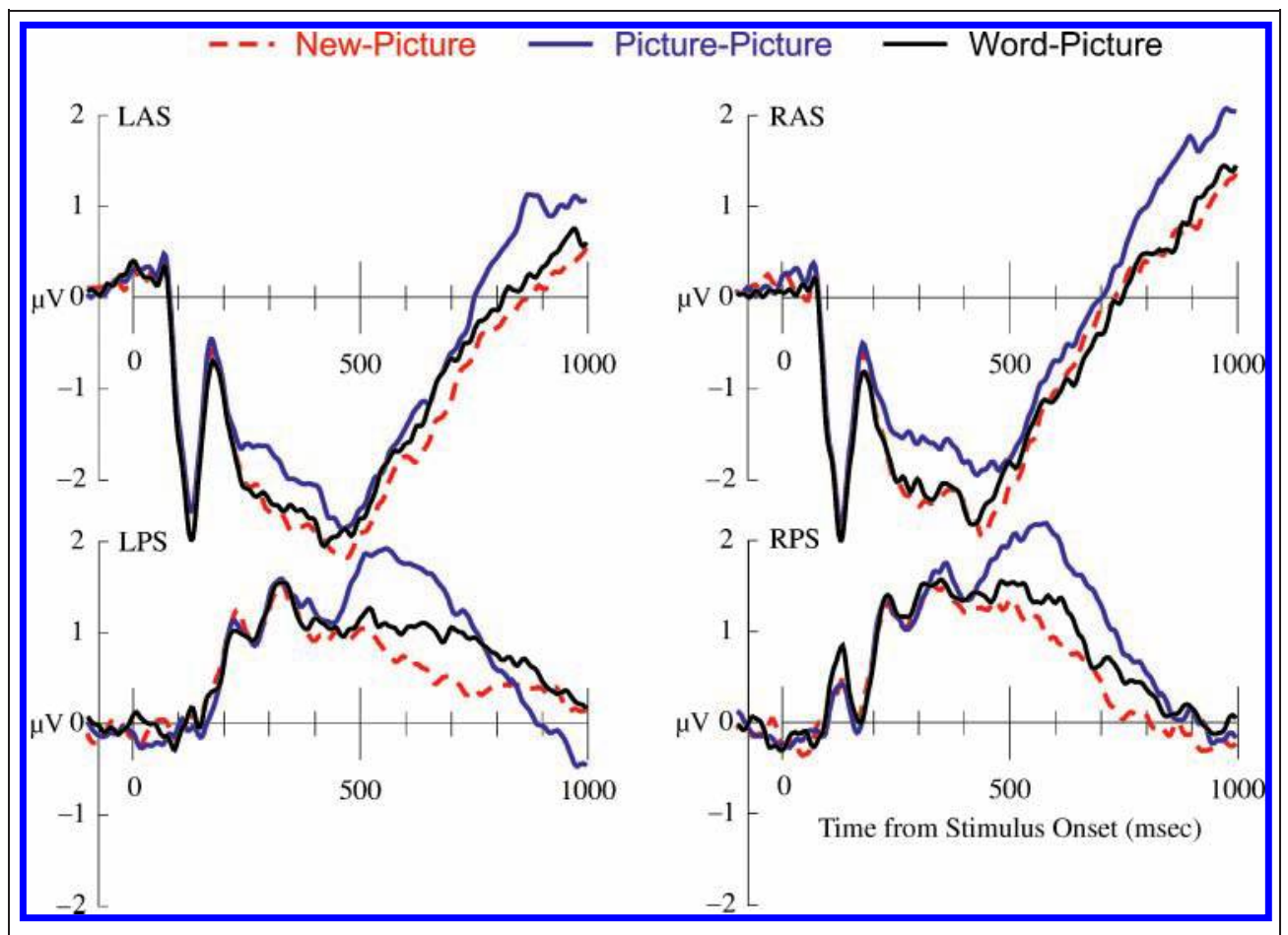


Figure 7. Topographic maps of old/new differences from Experiment 2.

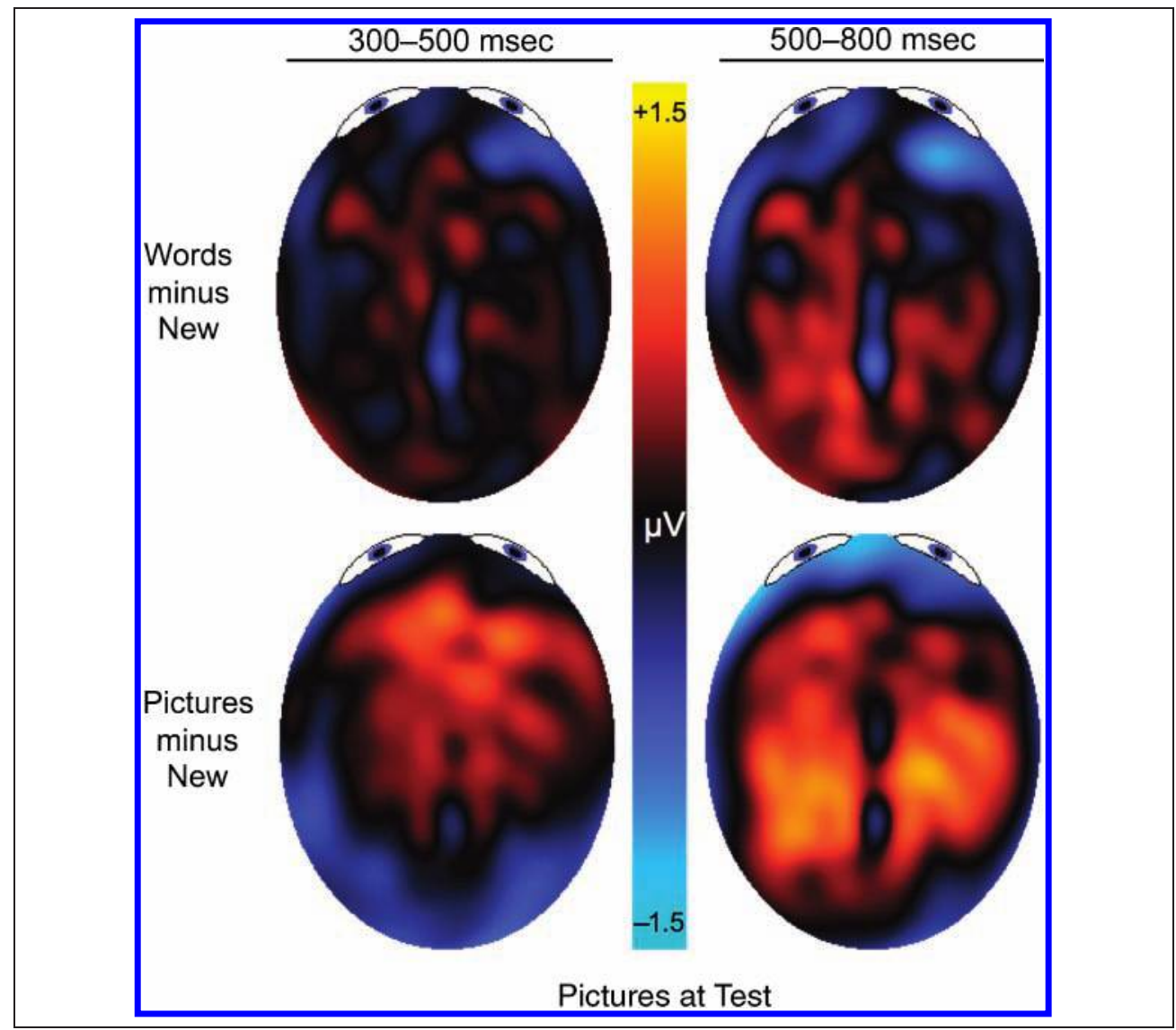

hemisphere was not significant $[F(2,56)<1, M S E=$ 0.17]. Pairwise comparisons indicate that the FN400 old/ new differences were significant for studied pictures over each hemisphere (both $p<.01$ ), but were not significant for studied words over either hemisphere (see Figure $4 \mathrm{C}$ for mean amplitudes and Figure 6 for ERP waveforms).

Parietal old/new effect. The parietal effect was analyzed in a 3 Condition (new, word, picture) $\times 2$ Hemisphere (LPS, RPS) ANOVA from 500 to $800 \mathrm{msec}$. The main effect of condition was significant $[F(2,56)=17.66, M S E=0.70$, $p<.0001$ ], but the interaction between condition and hemisphere was not significant $[F(2,56)<1, M S E=$ 0.16]. Pairwise comparisons indicated that parietal old/ new differences were significant for both words and pictures over each hemisphere, but these differences were larger for pictures than for words (all $p<.01$; Figure 4D).

Topographic analysis. Range-normalized old/new differences were analyzed in a 2 Time (300-500, 500$800 \mathrm{msec}) \times 2$ Condition (picture-new, word-new) $\times 2$ Hemisphere $\times 2$ Anterior/Posterior $\times 2$ Inferior/Superior repeated measures ANOVA. Several lower-order interactions were observed, but their interpretations were superseded by a significant Time $\times$ Condition $\times$ Anterior/ Posterior $\times$ Inferior/Superior interaction $[F(1,28)=$ 5.28, $M S E=0.58, p<.05]$. As can be observed in the topographic map of old/new differences (Figure 7 ), the picture $>$ word advantage was largest over anterior, superior regions at the time of the FN400 (in accord with the regions of interest in the main analyses), whereas the picture $>$ word advantage was largest over posterior, superior regions at the time of the parietal effects (also consistent with the regions of interest). Thus, although the FN400 and parietal effects were not dissociated by the word/picture manipulation in the present experiment, as predicted, typical spatio-temporal differences were observed.

\section{Discussion}

Experiment 2 tested recognition memory with pictures following study lists containing pictures and words. As predicted, each dependent measure of interest was enhanced for studied pictures over studied words: accuracy, the FN400 ERP old/new effect, and the parietal old/new effect. ERP laterality effects predicted from the results of Experiment 1 were not observed, thus either the Experiment 1 laterality effects were unreliable or our interpretation of them lead to erroneous predictions, as discussed further below.

\section{GENERAL DISCUSSION}

The picture superiority effect was observed in two recognition memory experiments: Accuracy was higher for 
studied pictures than studied words when either words (Experiment 1) or pictures (Experiment 2) were present at test. 300-500 msec mid-frontal FN400 ERP old/new effects, hypothesized to be related to familiarity, were enhanced by study/test congruity such that they were larger when perceptual formats matched (word/word or picture/ picture) than when they mismatched (picture/word or word/picture). 500-800 msec parietal ERP old/new effects, hypothesized to be related to recollection, were enhanced when pictures rather than words were studied, regardless of whether words or pictures were tested. These results have implications for understanding picture superiority, characterizing the functional correlates of the FN400 and parietal ERP old/new effects, and differentiating singlefrom dual-process theories of recognition memory. Each will be discussed in turn.

\section{Picture Superiority}

Accuracy was higher for studied pictures than studied words, regardless of whether words or pictures were tested. The picture superiority effect occurring even when words were tested strongly suggests that the effect primarily arises from encoding, rather than retrieval, differences between pictures and words, as has been observed in numerous other studies (Hockley, 2008; Boldini et al., 2007; Stenberg et al., 1995; Madigan, 1983; Paivio, 1976; Snodgrass \& McClure, 1975). However, more radically altering retrieval demands by changing to something other than recognition or recall tests can also modulate or even reverse picture superiority (Weldon et al., 1989; Weldon \& Roediger, 1987). The 500-800 msec parietal ERP old/new effect paralleled the accuracy results such that it also was enhanced when pictures rather than words were studied, both when pictures or words were tested. Given previous evidence that the parietal old/new effect is related to recollection (reviewed by, Rugg \& Curran, 2007; Curran, Tepe, et al., 2006; Mecklinger, 2006; Friedman \& Johnson, 2000; Mecklinger, 2000), these results uphold previous behavioral indications that picture superiority arises from a recollection advantage for pictures over words (Boldini et al., 2007; McBride \& Anne Dosher, 2002; Rajaram, 1996; Dewhurst \& Conway, 1994). Thus, the present results are consistent with the perspective that picture superiority bolsters encoding processes that facilitate recollection.

A recollective account is generally consistent with distinctiveness theories of the picture superiority effect (Mintzer \& Snodgrass, 1999; Weldon et al., 1989; Weldon \& Roediger, 1987; Nelson et al., 1976). A related line of research on "the distinctiveness heuristic" has examined the extent to which the recollection of distinctive information can reduce false memory (reviewed by Gallo, 2006; Schacter \& Wiseman, 2006). For example, in the Deese/Roediger-McDermott (DRM) paradigm (Roediger \& McDermott, 1995; Deese, 1959), presenting pictures rather than visual words along with items on an auditory study list reduces false recogni- tion of semantically related lures (Schacter, Israel, \& Racine, 1999). Using a modified source memory task, it has been suggested that this distinctiveness heuristic taps into recollection, rather than familiarity (Gallo et al., 2004, 2007).

Other research has suggested that both familiarity and recollection may be enhanced by distinctiveness when distinctiveness has been manipulated several ways other than comparing pictures and words (Nyhus \& Curran, 2009; Kishiyama \& Yonelinas, 2006). It is possible that distinctiveness differences between words and pictures do not emerge in familiarity-based measures because distinctiveness is outweighed by familiarity's sensitivity to study/test congruence. As we noted earlier, an especially interesting aspect of the picture superiority effect observed in designs like that of Experiment 1 is that the distinctiveness of the picture/word condition overpowers the study/test congruence of the word/word condition. Distinctiveness appears to overpower congruence for recollection to produce a picture superiority effect on accuracy, but congruence appears to overpower distinctiveness for familiarity.

In summary, the presently observed advantage for pictures over words in both accuracy and the parietal ERP old/new effect is consistent with picture superiority arising from encoding distinctive attributes of pictures that enhance recollection. This is consistent with previous indications that picture superiority is associated with recollection and distinctiveness.

\section{Functional Characteristics of FN400 and Parietal ERP Old/New Effects}

In the present experiments, $300-500 \mathrm{msec}$ mid-frontal FN400 ERP old/new effects benefited from study/test congruity, such that they were larger when study and test format were the same than different. This result is consistent with previous ERP studies comparing recognition memory for pictures and words (Ally \& Budson, 2007; Schloerscheidt \& Rugg, 2004), as well as consistent with other manipulations of study/test format (Nyhus \& Curran, 2009; Ecker et al., 2007a, 2007b; Groh-Bordin et al., 2006). The sensitivity of the FN400 to changes in perceptual format is difficult to reconcile with the view that the FN400 is related to conceptual priming (Paller, Voss, \& Boehm, 2007) because a purely conceptual process should be immune to perceptual format changes. FN400 effects cannot be described as either purely perceptual or purely conceptual. Although this effect varies with perceptual format, it can still be observed when study/test format changes (Curran \& Dien, 2003). In the present experiments, the right hemisphere FN400 old/new effects in both experiments were observed only when the study/ test format matched. Left hemisphere FN400 old/new differences also occurred when the format matched, but were transferred across formats in Experiment 1 (pictureword) and not in Experiment 2 (word-picture). One possible explanation of this asymmetry is that subjects named 
the pictures during study, so perhaps a verbal memory trace was encoded (or even a visual orthographic trace via visual word-form imagery) when pictures were studied, which transferred effectively when words were tested (Experiment 1). When words were studied, it may be improbable to generate a sufficiently specific visual image that would effectively transfer to the picture test format (Experiment 2). Thus, the left hemisphere representations may not be completely abstract, as we hypothesized prior to Experiment 2, but may depend on study conditions fostering a memory representation that is congruent with the test format. It is notable that the higher discrimination accuracy in Experiment 1 than in Experiment 2 is consistent with the presence of both cross-format and within-format FN400 effects in Experiment 1, but only within-format effects in Experiment 2.

The existing literature on possible picture superiority effects on tests of conceptual implicit memory has yielded mixed results. Early studies failed to find a picture superiority effect on tests of conceptual implicit memory (McDermott \& Roediger, 1996; Weldon \& Coyote, 1996). Later studies indicated that picture superiority could be observed with some combination of study/test tasks, but not others. Most pertinent to the present experiments, which both required subjects to name the stimuli aloud during study, one study showed that naming during study elicited a picture superiority effect when the test task was category-cued generation but not when the test task was category-cued verification (Vaidya \& Gabrieli, 2000). Another study involving naming during study and general knowledge questions during test only observed a picture superiority effect when the question probed distinctive features of the target items (e.g., "What animal has large eyes?" for the target "owl") (Hamilton \& Geraci, 2006). Given the absence of a specific test of implicit conceptual memory in the present recognition experiments, it is difficult to ascertain whether or not conceptual priming processes would show a picture superiority effect under the present conditions. However, as summarized earlier, the dependence of the FN400 on perceptual study/test format is inconsistent with what would be predicted from any purely conceptual process because insensitivity to physical format has been a defining feature of conceptual implicit memory from its earliest inceptions (Blaxton, 1989). Conceptual representations might differ between a generic word and its particular instantiation within a picture, but that perspective still makes it difficult to explain the complete absence of FN400 old/new differences in the word/ picture conditions of Experiment 2. Even if these conceptual representations are not identical, they should have enough overlap to support conceptual priming.

The 500-800 msec parietal ERP old/new effect was larger when pictures than words were studied, regardless of test format. As already discussed, this pattern of results is consistent with an account of the picture superiority effect whereby recollection benefits from distinctive encoding. This pattern is generally consistent with previous ERP stud- ies of the picture superiority effect (Ally \& Budson, 2007; Schloerscheidt \& Rugg, 2004), but the present results are statistically clearer. Larger parietal old/new effects for studied pictures than studied words are consistent with other research showing that the magnitude of the parietal old/ new effect increases with the amount of information that is recollected from the study episode (Vilberg, Moosavi, \& Rugg, 2006; Wilding, 2000). For example, Vilberg et al. (2006) had subjects study pairs of pictures followed by a modified remember/know test with single pictures. The parietal old/new effect was larger when subjects recollected the associated pictures than when they just remembered other information from the study episode. Similarly, it is reasonable to assume in the present experiments that there was more information to recollect about studied pictures than studied words.

Although the present results are highly consistent with previous investigations of FN400 and parietal ERP old/new effects, the results of Experiment 1 further provide particularly strong evidence for a crossover double dissociation between the underlying processes. When words were tested, studying words versus pictures had opposite effects on the two components. FN400 old/new differences were larger for studied words than studied pictures, but parietal old/new differences were larger for studied pictures than studied words. The word/picture differences were significant for each component separately, as was the component by word/picture interaction when the FN400 and parietal effects were directly compared. We know of only one other crossover double dissociation between these components reported in the literature (Jager et al., 2006).

\section{Single- versus Dual-process Theories}

As is evident from the discussion thus far, we prefer a dualprocess explanation of these results, such that familiarity processes reflected by FN400 old/new differences benefit from study/test congruity, whereas recollection processes reflected by parietal old/new differences benefit from encoding the distinctive features of pictures. ${ }^{4}$ Dual-process interpretations of the FN400 and parietal ERP old/new effects have previously emphasized spatio-temporal differences as well as single dissociations (reviewed by, Rugg \& Curran, 2007; Curran, Tepe, et al., 2006; Mecklinger, 2006; Friedman \& Johnson, 2000; Mecklinger, 2000). The weight of these arguments has been compelling, but still amenable to single-process explanations. Spatio-temporal differences between the components are consistent with the existence of separate underlying sources whose activity peaks at different times, but they can also be interpreted as consistent with a single process supported by a common set of neural generators whose relative strengths change over time (Picton et al., 2000; Alain, Achim, \& Woods, 1999). For example, a single strength-based memory process might be supported by a distributed neural network including sources that primarily project to both mid-frontal (the primary source of FN400 old/new 
effects) and parietal (the primary source of parietal old/new effects) scalp locations. Thus, spatio-temporal differences alone do not rule out a single-process explanation.

Single dissociations are beset by the problem that an effect on one component is accompanied by a null effect on the other (Dunn \& Kirsner, 2003). Even if null effects could be trusted on statistical grounds, such single dissociations might not demonstrate clear qualitative differences between the components. A variable affecting the parietal old/new effect, but not the FN400, might be one whose influence grows over time, such that it weakly affects memory strength at the time of the FN400, but affects it more strongly at the time of the parietal effect. Conversely, a single dissociation in the opposite direction could be attributed to an earlier acting effect that diminishes over time. Similar interpretive problems exist with uncrossed double dissociations (Dunn \& Kirsner, 1988) such as findings that "remembering" selectively influenced the parietal effect, whereas sub-recollection confidence level selectively influenced the FN400 (Woodruff et al., 2006), and that name familiarity selectively influenced the FN400, whereas name fame selectively influenced the parietal effect (Stenberg et al., 2009). We agree that the results of Woodruff et al. (2006) provide strong evidence for separate familiarity and recollection process, especially because the confidence versus remembering manipulations provide clear a priori predictions concerning familiarity versus recollection. We also agree that the results of Stenberg et al. (2009) are highly consistent with the dual-process perspective because they found corroborating behavioral results favoring the dual-process account and contradicting a conceptual priming account of the FN400 (for further debate, see Lucas, Voss, \& Paller, 2010; Stenberg, Johansson, Hellman, \& Rosén, 2010). However, it is still possible that the null results observed in these experiments reflect weak effects of these variables that went undetected. The present Experiment 1 results show that the same variable affected both ERP components, but in opposite directions, so it is not amenable to any such arguments based on weak effects that are statistically undetectable (this advantage also applies to the crossover interaction observed by Jager et al., 2006). Any theory of these results needs to explain why studying words helps the earlier process, whereas studying pictures helps the later process, in addition to addressing the topographic differences that are suggestive of different neuronal sources.

One specific single-process explanation of these ERP components contends that the FN400 reflects memory strength, whereas the parietal effects reflect decision processes that may influence criterion setting and/or response confidence (Finnigan, Humphreys, Dennis, \& Geffen, 2002). Because our stimulus manipulation occurred entirely during encoding, word/picture differences cannot be explained in terms of response bias (although response bias may contribute to differences observed between experiments comparing words vs. pictures as test items).
Although confidence is likely higher for hits given to studied pictures than studied words, differential confidence alone cannot explain the accuracy advantage that was observed for pictures and reflected in the parietal old/new effects.

It is still possible to explain the double dissociation with a single-process model if one assumes that perceptual information about studied words accrues earlier than information about pictures (see Boldini et al.'s explanation of their own results using the FESTHER model of Brockdorff \& Lamberts, 2000). The more general form of this explanation (i.e., extending to both of the present experiments) would be that perceptual information, which influences the FN400 and causes early perceptual congruity effects, is processed earlier than the information that underlies the distinctive encoding advantage observed for pictures. This could explain the time-course differences, and the topographic differences might reflect storage of these different types of information in distinct networks. Perhaps differences between FN400 and parietal effects similarly reflect differences between perceptual and conceptual information, but this is unlikely to explain all differences between the FN400 and parietal effects because both components can be influenced by both perceptual and conceptual variables (Nyhus \& Curran, 2009; Ecker et al., 2007a, 2007b; Groh-Bordin et al., 2006; Rugg, Allan, \& Birch, 2000).

In summary, we believe the present crossover double dissociation is strongly consistent with the dual-process perspective. As discussed above, we do not wish to argue that such a double dissociation cannot be explained by a single-process theory, but we find the dual-process account to be most convincing.

\section{Conclusion}

The present results are consistent with an explanation of the picture superiority effect whereby memory accuracy benefits from encoding the distinctive attributes of pictures in a manner that enhances their later recollection, as indexed by the parietal ERP old/new effect. On the other hand, familiarity as indexed by the FN400 old/new effect was primarily sensitive to study/test congruity rather than picture superiority. When recognition was tested with words in Experiment 1, opposite effects of studying words versus studying pictures on the FN400 versus parietal old/ new effect provide strong evidence for a crossover double dissociation between these components that is best explained by a dual-process perspective.

\section{Acknowledgments}

This research was funded by NIH Grant MH64812, NSF grant \#SBE-0542013 to the Temporal Dynamics of Learning Center (an NSF Science of Learning Center), and by a University of Colorado's Summer Undergraduate Research Fellowship. We thank Grit Herzmann, Erika Nyhus, Megan Freeman, Emily Freeman, 
and Simon Dennis for helpful comments; Anna Szekely for help with the IPNP on-line stimulus database (http://crl.ucsd.edu/ aszekely/ipnp/, Szekely et al., 2004); Casey DeBuse, Brent Young, and Chris Bird for research assistance; and Alex Eichenbaum, Megan Freeman, Will Hall, Sarah Jirkovsky, Brandon May, Portia Payne, Brandon Saranik, Cara Scott, Masataka Umeda, and Richard Yaner for help with subject testing.

Reprint requests should be sent to Tim Curran, Department of Psychology and Neuroscience, 345 UCB, University of Colorado at Boulder, Boulder, CO 80309, or via e-mail: tim.curran@ colorado.edu.

\section{Notes}

1. These percentages are $\operatorname{Pr}$ (\%Hits - \%False Alarms) rates for $\mathrm{A} \& \mathrm{~B}$ who did not report separate hit and false alarms rates, but hit rates for S\&R. Comparable Pr values can be computed for S\&R's results by subtracting the common false alarm rate of $13 \%$.

2. A reviewer suggested that we conduct further analyses at locations and time points where the effects were maximal in these particular experiments, in addition to the a priori selected locations in the primary analyses. When analyses focused on the locations at which the old/new effects were maximal across both experiments, all effects reported in the primary analyses of both experiments were replicated. When FN400 analyses were conducted from 400 to 600 msec for Experiment 1, all effects reported in the primary analyses were replicated except for one that became only marginally significant, as specified later.

3. This Condition $\times$ Hemisphere interaction was only marginally significant $(p=.059)$ when the analysis focused on locations where the FN400 was maximal in a later window (400-600 msec). However, all the ensuing pairwise comparisons did replicate. 4. Even if one maintains the view that the FN400 is related to conceptual priming rather than familiarity, the following arguments about the importance of the double dissociation are still of interest. Single-process theories of the relationship between explicit and implicit memory are still advanced (Berry, Shanks, \& Henson, 2008; Butler \& Berry, 2001); thus evidence of the separability of the processes underlying the FN400 and parietal ERP effects is relevant from either theoretical perspective.

\section{REFERENCES}

Alain, C., Achim, A., \& Woods, D. L. (1999). Separate memoryrelated processing for auditory frequency and patterns. Psychophysiology, 36, 737-744.

Ally, B. A., \& Budson, A. E. (2007). The worth of pictures: Using high density event-related potentials to understand the memorial power of pictures and the dynamics of recognition memory. Neuroimage, 35, 378-395.

Azimian-Faridani, N., \& Wilding, E. L. (2006). The influence of criterion shifts on electrophysiological correlates of recognition memory. Journal of Cognitive Neuroscience, 18, 1075-1086.

Berry, C. J., Shanks, D. R., \& Henson, R. N. (2008). A unitary signal-detection model of implicit and explicit memory. Trends in Cognitive Sciences, 12, 367-373.

Blaxton, T. A. (1989). Investigating dissociations among memory measures: Support for a transfer appropriate processing framework. Lournal of Experimental Psychology: Learning. Memorv and Cognition, 15, 657-668.

Boldini, A., Russo, R., Punia, S., \& Avons, S. E. (2007). Reversing the picture superiority effect: A speed-accuracy tradeoff study of recognition memory. Memorv \& Cognition, 35, 113-123.
Brockdorff, N., \& Lamberts, K. (2000). A feature-sampling account of the time course of old-new recognition judgments. Journal of Experimental Psychology: Learning. Memorv and Cognition, 26, 77-102.

Budson, A. E., Droller, D. B., Dodson, C. S., Schacter, D. L., Rugg, M. D., Holcomb, P. J., et al. (2005). Electrophysiological dissociation of picture versus word encoding: The distinctiveness heuristic as a retrieval orientation. Lournal of Cognitive Neuroscience, 17, 1181-1193.

Butler, L. T., \& Berry, D. C. (2001). Implicit memory: Intention and awareness revisited. Trends in Cognitive Sciences, 5, 192-197.

Curran, T. (2000). Brain potentials of recollection and familiarity. Memorv \& Cognition, 28, 923-938.

Curran, T. (2004). Effects of attention and confidence on the hypothesized ERP correlates of recollection and familiarity. Neuropsychologia, 42, 1088-1106.

Curran, T., \& Cleary, A. M. (2003). Using ERPs to dissociate recollection from familiarity in picture recognition. Cognitive Brain Research, 15, 191-205.

Curran, T., DeBuse, C., Woroch, B., \& Hirshman, E. (2006). Combined pharmacological and electrophysiological dissociation of familiarity and recollection. Lournal of Neuroscience, 26, 1979-1985.

Curran, T., \& Dien, J. (2003). Differentiating amodal familiarity from modality-specific memory processes: An ERP study. Psvchophvsiologv, 40, 979-988.

Curran, T., \& Hancock, J. (2007). The FN400 indexes familiaritybased recognition of faces. Neuroimage, 36, 464-471.

Curran, T., Tepe, K. L., \& Piatt, C. (2006). ERP explorations of dual processes in recognition memory. In H. D. Zimmer, A. Mecklinger, \& U. Lindenberger (Eds.), Binding in buman memory: A neurocognitive approach (pp. 467-492). Oxford: Oxford University Press.

Deese, J. (1959). On the prediction of occurrence of particular verbal intrusions in immediate recall. Journal of Experimental Psvchologv, 58, 17-22.

Dewhurst, S. A., \& Conway, M. A. (1994). Pictures, images, and recollective experience. Iournal of Experimental Psvchologv: Learning. Memorv and Cognition, 20, 1088-1098.

Dien, J. (1998). Issues in the application of the average reference: Review, critiques, and recommendations. Behavior Research Methods. Instruments and Computers, 30, 34-43.

Dunn, J. C. (2004). Remember-know: A matter of confidence. Psvchological Review, 111, 524-542.

Dunn, J. C., \& Kirsner, K. (1988). Discovering functionally independent mental processes: The principal of reversed association. Psvchological Review, 95, 91-101.

Dunn, J. C., \& Kirsner, K. (2003). What can we infer from double dissociations? Cortex, 39, 1.

Düzel, E., Yonelinas, A. P., Mangun, G. R., Heinze, H. J., \& Tulving, E. (1997). Event-related potential correlates of two states of conscious awareness in memory. Proceedings of the National Academv of Sciences. U.S.A. 94, 5973-5978.

Ecker, U. K., Zimmer, H. D., \& Groh-Bordin, C. (2007a). Color and context: An ERP study on intrinsic and extrinsic feature binding in episodic memory. Memory \& Cognition, $35,1483-1501$.

Ecker, U. K., Zimmer, H. D., \& Groh-Bordin, C. (2007b). The influence of object and background color manipulations on the electrophysiological indices of recognition memory. Brain Research, 1185, 221-230.

Eichenbaum, H., Yonelinas, A. P., \& Ranganath, C. (2007). The medial temporal lobe and recognition memory. Annual Review of Neuroscience, 30, 123-152. 
Finnigan, S., Humphreys, M. S., Dennis, S., \& Geffen, G. (2002) ERP "old/new" effects: Memory strength and decisional factor(s). Neuropsychologia, 40, 2288-2304.

Friedman, D., \& Johnson, R., Jr. (2000). Event-related potential (ERP) studies of memory encoding and retrieval: A selective review. Microscopv Research and Technique, 51, 6-28.

Gallo, D. A. (2006). Associative illusions of memory: False memory research in DRM and related tasks. New York: Psychology Press.

Gallo, D. A., Cotel, S. C., Moore, C. D., \& Schacter, D. L. (2007). Aging can spare recollection-based retrieval monitoring: The importance of event distinctiveness. Psychology and Aging, 22, 209-213.

Gallo, D. A., Weiss, J. A., \& Schacter, D. L. (2004). Reducing false recognition with criterial recollection tests: Distinctiveness heuristic versus criterion shifts. Journal of Memorv and Language, 51, 473-493.

Geisser, S., \& Greenhouse, S. W. (1958). An extension of Box's results on the use of the $\mathrm{F}$ distribution in multivariate analyses. Annals of Mathematical Statistics, 29, 885-891.

Gratton, G., Coles, M. G., \& Donchin, E. (1983). A new method for off-line removal of ocular artifact. Electroencephalography and Clinical Neuropbusiology 55, 468-484.

Groh-Bordin, C., Zimmer, H. D., \& Ecker, U. K. (2006). Has the butcher on the bus dyed his hair? When color changes modulate ERP correlates of familiarity and recollection. Neuroimage, 32, 1879-1890.

Hamilton, M., \& Geraci, L. (2006). The picture superiority effect in conceptual implicit memory: A conceptual distinctiveness hypothesis. American Iournal of Psychology 119, 1-20.

Hintzman, D. L., \& Curran, T. (1994). Retrieval dynamics of recognition and frequency judgments: Evidence for separate processes of familiarity and recall. Lournal of Memory and Language, 33, 1-18.

Hirshman, E. (1995). Decision processes in recognition memory: Criterion shifts and the list-strength paradigm. Lournal of Experimental Psvchologv: Learning. Memorv. and Cognition, 21, 302-313.

Hockley, W. E. (2008). The picture superiority effect in associative recognition. Memory \& Cognition, 36, 1351-1359.

Hornberger, M., Morcom, A. M., \& Rugg, M. D. (2004). Neural correlates of retrieval orientation: Effects of study-test similarity. Iournal of Cognitive Neuroscience, 16, 1196-1210.

Jager, T., Mecklinger, A., \& Kipp, K. H. (2006). Intraand inter-item associations doubly dissociate the electrophysiological correlates of familiarity and recollection. Neuron, 52, 535-545.

Junghöfer, M., Elbert, T., Tucker, D. M., \& Braun, C. (1999). The polar average reference effect: A bias in estimating the head surface integral in EEG recording. Clinical Neuropbysiology, 110, 1149-1155.

Kishiyama, M. M., \& Yonelinas, A. P. (2006). Stimulus novelty effects on recognition memory: Behavioral properties and neuroanatomical substrates. In R. R. Hunt \& J. B. Worthen (Eds.), Distinctiveness and memory (pp. 381-404). New York: Oxford University Press.

Laeng, B., Overvoll, M., \& Steinsvik, O. (2007). Remembering 1500 pictures: The right hemisphere remembers better than the left. Brain and Cognition, 63, 136-144.

Lucas, H. D., Voss, J. L., \& Paller, K. A. (2010). Familiarity or conceptual priming? Good question! Comment on Stenberg, Hellman, Johansson, and Rosén (2009). Journal of Cognitive Neuroscience, 22, 615-617.

Madigan, S. (1983). Picture memory. In J. C. Yuille (Ed.), Imagery, memory, and cognition: Essays in honor of Allan Paivio (pp. 65-89). Hillsdale, NJ: Erlbaum.
Marsolek, C. J., Squire, L. R., Kosslyn, S. M., \& Lulenski, M. E. (1994). Form-specific explicit and implicit memory in the right cerebral hemisphere. Neuropsvchologv 8, 588-597.

McBride, D. M., \& Anne Dosher, B. (2002). A comparison of conscious and automatic memory processes for picture and word stimuli: A process dissociation analysis. Consciousness \& Cognition, 11, 423-460.

McCarthy, G., \& Wood, C. C. (1985). Scalp distributions of event-related potentials: An ambiguity associated with analysis of variance models. Electroencephalography and Clinical Neurophysiology, 62, 203-208.

McDermott, K. B., \& Roediger, H. L., III (1996). Exact and conceptual repetition dissociate conceptual memory tests: Problems for transfer appropriate processing theory. Canadian Journal of Experimental Psychology, 50, 57-71.

McElree, B., Dolan, P. O., \& Jacoby, L. L. (1999). Isolating the contributions of familiarity and source information to item recognition: A time-course analysis. Journal of Experimental Psychologv: Learning. Memorv and Cognition, 25, 563-582.

Mecklinger, A. (2000). Interfacing mind and brain: A neurocognitive model of recognition memory. Psuchophysiology, 37, 565-582.

Mecklinger, A. (2006). Electrophysiological measures of familiarity memory. Journal of Clinical EEG \& Neuroscience, 37, 292-299.

Metcalfe, J., Funnell, M., \& Gazzaniga, M. S. (1995). Right-hemisphere memory superiority: Studies of a split-brain patient. Psvchological Science, 6, 157-164.

Mintzer, M. Z., \& Snodgrass, J. G. (1999). The picture superiority effect: Support for the distinctiveness model. American Iournal of Psvchology, 112, 113-146.

Nelson, D. L., Reed, V. S., \& Walling, J. R. (1976). Pictorial superiority effect. Iournal of Experimental Psychology: Human Learning and Memory, 25, 523-528.

Nyhus, E., \& Curran, T. (2009). Semantic and perceptual effects on recognition memory: Evidence from ERP. Brain Research, 1283, 102-114

Paivio, A. (1976). Imagery in recall and recognition. In J. Brown (Ed.), Recall and recognition. New York: Wiley.

Paivio, A. (1986). Mental representation: A dual coding approach. Hillsdale, NJ: Erlbaum.

Paller, K. A., Voss, J. L., \& Boehm, S. G. (2007). Validating neural correlates of familiarity. Trends in Cognitive Sciences 11, 243-250.

Picton, T. W., Bentin, S., Berg, P., Donchin, E., Hillyard, S. A., Johnson, R., Jr., et al. (2000). Guidelines for using human event-related potentials to study cognition: Recording standards and publication criteria. Psychophysiology, 37, $127-152$

Rajaram, S. (1996). Perceptual effects on remembering: Recollective processes in picture recognition memory. Lournal of Experimental Psvchologv: Learning. Memory and Cognition, 22, 365-377.

Reder, L. M., Donavos, D. K., \& Erickson, M. A. (2002). Perceptual match effects in direct tests of memory: The role of contextual fan. Memorv \& Cognition, 30, 312-323.

Roediger, H. L., \& McDermott, K. B. (1995). Creating false memories: Remembering words not presented in lists. Lournal of Experimental Psychologv: Learning. Memorv. and Cognition, 21, 803-814.

Rugg, M. D., Allan, K., \& Birch, C. S. (2000). Electrophysiological evidence for the modulation of retrieval orientation by depth of study processing. Iournal of Cognitive Neuroscience, 12, 664-678.

Rugg, M. D., \& Curran, T. (2007). Event-related potentials and recognition memory. Trends in Cognitive Sciences, 11, 251-257. 
Rugg, M. D., Schloerscheidt, A. M., \& Mark, R. E. (1998). An electrophysiological comparison of two indices of recollection. Journal of Memory and Language, 39, 47-69.

Schacter, D. L., Israel, L., \& Racine, C. (1999). Suppressing false recognition in younger and older adults: The distinctiveness heuristic. Journal of Memory and Language, 40, 1-24.

Schacter, D. L., \& Wiseman, A. L. (2006). Reducing memory errors: The distinctiveness heuristic. In R. R. Hunt \& J. B. Worthen (Eds.), Distinctiveness and memory (pp. 89-107). New York: Oxford University Press.

Schloerscheidt, A. M., \& Rugg, M. D. (2004). The impact of change in stimulus format on the electrophysiological indices of recognition. Neuropsvchologia, 42, 451-466.

Senkfor, A. J., \& Van Petten, C. (1998). Who said what? An event-related potential investigation of source and item memory. Journal of Experimental Psychology: Learning. Memorv. and Cognition, 24, 1005-1025.

Smith, M. E. (1993). Neurophysiological manifestations of recollective experience during recognition memory judgments. Lournal of Cognitive Neuroscience, 5, 1-13.

Snodgrass, J. G., \& McClure, P. (1975). Studied storage and retrieval properties of pictures and words within a recognition memory paradigm. Lournal of Experimental Psvchology: Human Learning and Memorv, 1, 521-529.

Snodgrass, J. G., \& Vanderwart, M. (1980). A standardized set of 260 pictures: Norms for name agreement, image agreement, familiarity, and visual complexity. Lournal of Experimental Psychology: Human Learning and Memorv, 6, 174-215.

Srinivasan, R., Nunez, P. L., Silberstein, R. B., Tucker, D. M., \& Cadusch, P. J. (1996). Spatial sampling and filtering of EEG with spline-Laplacians to estimate cortical potentials. Brain Todograbby, 8, 355-366.

Stenberg, G., Hellman, J., Johansson, M., \& Rosén, I. (2009). Familiarity or conceptual priming: Event-related potentials in name recognition. Journal of Cognitive Neuroscience, 21, $447-460$.

Stenberg, G., Johansson, M., Hellman, J., \& Rosén, I. (2010). "Do you see yonder cloud?"-On priming concepts, a new test and a familiar outcome. Reply to Lucas et al.: "Familiarity or conceptual priming? Good question! Comment on Stenberg, Hellman, Johansson, and Rosén (2009)". Iournal of Cognitive Neuroscience, 22, 618-620.

Stenberg, G., Radeborg, K., \& Hedman, L. R. (1995). The picture superiority effect in a cross-modality recognition task. Memory \& Cognition, 23, 425-441.
Stretch, V., \& Wixted, J. T. (1998). On the difference between strength-based and frequency-based mirror effects in recognition memory. Lournal of Experimental Psvchology: Learning. Memory and Cognition, 24, 1379-1396.

Szekely, A., Jacobsen, T., D’Amico, S., Devescovi, A., Andonova, E., Herron, D., et al. (2004). A new on-line resource for psycholinguistic studies. Iournal of Memorv and Language. 51, 247-250.

Trott, C. T., Friedman, D., Ritter, W., Fabiani, M., \& Snodgrass, J. G. (1999). Episodic priming and memory for temporal source: Event-related potentials reveal age-related differences in prefrontal functioning. Psvchologv \& Aging 14, 390-413.

Vaidya, C. J., \& Gabrieli, J. D. (2000). Picture superiority in conceptual memory: Dissociative effects of encoding and retrieval tasks. Memorv \& Cognition, 28, 1165-1172.

Vilberg, K. L., Moosavi, R. F., \& Rugg, M. D. (2006). The relationship between electrophysiological correlates of recollection and amount of information retrieved. Brain Research, 1122, 161-170.

Weldon, M. S., \& Coyote, K. C. (1996). Failure to find the picture superiority effect in implicit conceptual memory tests. Iournal of Experimental Psychology: Learning. Memory and Cognition, 22, 670-686.

Weldon, M. S., \& Roediger, H. L. (1987). Altering retrieval demands reverses the picture superiority effect. Memorv E Cognition, 15, 269-280.

Weldon, M. S., Roediger, H. L., \& Challis, B. H. (1989). The properties of retrieval cues constrain the picture superiority effect. Memory \& Cognition, 17, 95-105.

Wilding, E. L. (2000). In what way does the parietal ERP old/new effect index recollection? International Iournal of Psychopbysiology, 35, 81-87.

Wilding, E. L., \& Rugg, M. D. (1996). An event-related potential study of recognition memory with and without retrieval of source. Brain, 119, 889-905.

Wixted, J. T. (2007). Dual-process theory and signal-detection theory of recognition memory. Psvchological Review 114, 152-176.

Woodruff, C. C., Hayama, H. R., \& Rugg, M. D. (2006). Electrophysiological dissociation of the neural correlates of recollection and familiarity. Brain Research, 1100, $125-135$.

Yonelinas, A. P. (2002). The nature of recollection and familiarity: A review of 30 years of research. Iournal of Memory and Language, 46, 441-517. 